\title{
APRESENTAÇÃO DO DOSSIÊ A EDUCAÇÃO NOS ESTADOS UNIDOS: DO SÉCULO 19 AO SÉCULO 20
}

DOI: http://dx.doi.org/10.1590/2236-3459/204811.16

\author{
EDUCATION IN THE UNITED STATES: \\ $19^{\circ}$ CENTURY TO $20^{\circ}$ CENTURY DOSSIER PRESENTATION
}

\author{
Mirian Jorge Warde \\ Universidade Federal de São Paulo - campus de Guarulhos, Brasil.
}

$\cos 80$

ste dossiê abrange uma coletânea de textos acerca da educação escolar nos Estados Unidos, com destaque à passagem do século 19 ao século 20 . Os autores e os temas foram pensados a partir de dois objetivos principais: primeiro, informar o leitor brasileiro a respeito da educação norte-americana a partir de perspectivas históricas valorosas; segundo, focalizar educação escolar norte-americana em um período e nas dimensões que têm sido de especial interesse aos historiadores brasileiros da educação.

Embora a literatura acadêmica repita qual um mantra que a educação em nossas plagas seja produto da influência de modelos estrangeiros, destacadamente franceses e norte-americanos, o leitor brasileiro não conta com bibliografia consistente que ofereça informações e análises para confirmar, refutar ou, ainda, lapidar aquele postulado. É também crítica a ausência de títulos equivalentes em um momento em que os educadores e pesquisadores da educação não podem mais ignorar a inserção do Brasil na cena internacional.

O leitor não encontrará aqui intenções ou procedimentos comparativos a conduzir as análises. Pelo contrário; o que se pretende com este dossiê é o exercício de análise do outro com o máximo de respeito possível - no sentido cognitivo - à alteridade. Não se trata de proposta original no que intenta; afinal, é só isso que os historiadores da cultura vêm recomendando há décadas: estranhar, desfamiliarizar. Admitir, mesmo que por hipótese, que a juntada da farinha com o fermento nem sempre prenuncia o nosso pão francês de cada dia. 
Aos autores foram estabelecidas regras singelas, truísmos para quem está familiarizado com as lidas historiográficas: apoiar os artigos em fontes originais e explorar a bibliografia disponível no que ela apresenta de mais consistente e relevante, não descurando de oferecer ao leitor indicações dos textos brasileiros que tratam do tema ou do seu em torno.

A escolha de mais autores brasileiros do que norte-americanos decorreu não só da intenção de quebrar a timidez ainda vigente nos nossos meios acadêmicos de estudar e pesquisar sobre o que se passa em outros países em matéria de educação; deriva também do interesse de reunir autores que têm acumulado conhecimento sobre a educação escolar nos Estados Unidos e, o que é especialmente interessante, autores que têm se utilizado de ferramentas conceituais e de método mais acuradas do que as verificadas em muitos títulos da historiografia educacional norte-americana.

Carla Simone Chamon apresenta o Paraíso das crianças: o kindergarten nos Estados Unidos entre meados do século 19 e início do 20. Nesse estudo, o que interessa em especial é a americanização do kindergarten alemão froebeliano. A autora informa que as primeiras instituições desse tipo apareceram nos Estados Unidos dos anos de 1850, por iniciativa de imigrantes alemães, uma vez que a presença desses imigrantes impactou estruturalmente a educação e as instituições de cultura norte-americanas; não casualmente, esse assunto reaparecerá em outro artigo do dossiê. Assim como veremos figuras como Pestalozzi, Stanley Hall, Dewey e outros que, sendo mobilizados por Chamon para compor a cena do início da educação infantil nos Estados Unidos, reaparecerão em outras cenas compostas pelos demais autores desse dossiê. Este trabalho explora de maneira competente os muitos conflitos envolvidos na implantação dos kindergartens nos Estados Unidos e as disputas no processo de incorporação dessa modalidade de instituição ao sistema público escolar norte-americano.

Como o próprio título indica, em As disputas pelo currículo e a renovação da escola primária nos Estados Unidos na transição do século 19 para o século 20, Rosa Fátima de Souza reconstitui os embates travados entre o fim do século 19 e o começo do século 20 em torno do currículo da escola elementar. Para a primeira cena, Souza traz os herbartianos, com destaque inovador aos irmãos McMurry, Francis Parker, John Dewey e Stanley Hall, envolvidos em contendas cuja relevância nacional indicia o lugar que estava sendo reservado à educação no projeto norte-americano rumo à hegemonia. Nesse artigo, o leitor ganha mais uma vez a oportunidade de desfazer a ideia de que teria havido uma "escola nova" onde estariam congraçados renovadores ou inovadores da educação norte-americana.

No seu artigo, Vera Teresa Valdemarin Modelos para a formação de professores nas páginas do Teachers College Record (1900-1921), percorre um caminho inédito para tratar com singularidade o muito visitado e ainda não devidamente equacionado tema da formação docente. Pelas páginas do periódico, Valdemarin dá a saber as posições em torno do assunto; aqui também, como há de se supor dado o caráter secularmente controvertido da matéria, a não homogeneidade de perspectivas sequer dentre o corpo docente do Teachers College. Apesar das divergências, ou em razão delas, o TCR mantém uma estratégia editorial que põe em circulação o intento comum de fazer do Teachers College da Columbia o centro de referência no campo da formação docente. As figuras destacadas neste trabalho reaparecerão neste dossiê inscritos em outras cenas. 
Com o trabalho de Maria das Graças M. Ribeiro, A educação superior norteamericana: gênese de um modelo, o leitor é chamado a conhecer o processo de hegemonização de um modelo de ensino superior como elemento chave do processo de construção da hegemonia norte-americana. Além de documentos oficiais, como o Morril Act de 1862, Ribeiro atenta para posições críticas de grande relevo teórico e histórico, como a de Thorstein Veblen, por meio de quem é dado a compreender como se amalgamaram, nos Estados Unidos, as esferas pública e privada no campo do ensino superior. Vale destacar, ainda, o que a autora apresenta sobre os land-grant colleges que marcam o início da presença do Estado na educação superior, assunto que já vem estudando há um tempo.

Mirian Jorge Warde, em Periodismo educacional: Estados Unidos, do século 19 às primeiras décadas do século 20, apresenta uma visão abrangente dos periódicos lançados desde o século 19 até os anos de 1920 no âmbito da educação. São destacadas as tendências prevalecentes em aspectos tais como editores, locais de produção e destinatários potenciais. $O$ artigo procura evidenciar a passagem da destinação predominantemente escolar para uma destinação mais diversificada na qual a especialização em subáreas do conhecimento, a expertise em pesquisa, a gramática acadêmica não são as únicas propensões, mas passam a estabelecer padrões de qualidade. Este artigo dialoga com os demais não tanto pela temática abarcada como também pelas pessoas, instituições e associações referidas.

Waye Urban, professor da renomada Universidade de Wisconsin, aqui apresenta um estudo sobre o tema de seu interesse: A Associação Nacional de Educação dos Estados Unidos da América. Urban oferece um entendimento sólido do que teria sido a trajetória da mais poderosa associação de educação nos Estados Unidos, em pleno funcionamento desde meados do século 19. Com este artigo, mais uma vez os dissensos, as polêmicas, os debates ocupam a cena ajudando, também, a desfazer as leituras esquematizadoras. Merecem destaques tensões que atravessam a NEA e que aparecem como motores de importantes confrontações: as de gênero e as étnico-raciais.

MIRIAN JORGE WARDE é professora visitante no Programa de Pós-Graduação em Educação da Universidade Federal de São Paulo - campus de Guarulhos. Pesquisador sênior do CNPq.

Endereço: Av. Monteiro Lobato, 679 - 07112-000 - Guarulhos - SP - Brasil.

E-mail: mjwarde@uol.com.br.

Recebido em 19 de junho de 2015.

Aceito em 4 de agosto de 2015. 